\title{
Physicalism, Not Scientism
}

\begin{abstract}
Alyssa Ney
For Scientism: Prospects and Problems, a volume to be published by Oxford University Press edited by Jeroen de Ridder, Rik Peels, and René van Woudenberg

\section{Introduction}

Physicalism, a position that has for some time been the received view in philosophy (certainly in contemporary metaphysics), is usually formulated roughly as the proposition that the world is simply the way physics says it is. As appealing an idea this is to many of those impressed by the history of successes of physical science, demystifying a range of phenomena from ordinary chemical reactions to the motions of stars and planets to biological processes in plants and animals, others view it as a form of scientism, and thus problematic, as scientism is a controversial and much maligned position. Although rough formulations of physicalism can make it look as if physicalism is simply a reductionist form of scientism, as I'll argue here, attention to more nuanced and plausible characterizations of the position will show this is not so.
\end{abstract}

As is well demonstrated by the contributions in this volume, scientism, like physicalism, may be understood in a variety of subtly different ways. The core idea I mean to be distinguishing from physicalism in the present paper is what Susan Haack has called that "kind of over-enthusiastic and uncritically deferential attitude towards science, an inability to see or an unwillingness to acknowledge its fallibility" (2012), and not just its fallibility but also its limitations. As Rik Peels argues in his "A Conceptual Map of Scientism," versions of scientism vary from one philosopher or scientist to another, but those seen to advocate scientism are typically those who believe that our scientific theories, or perhaps more narrowly, the physical sciences, should be expanded to cover 
more or perhaps all domains of inquiry, often because it is thought that science or scientific methods are best positioned to bring us reliable knowledge about the world. As a corollary, those who adopt the position commonly believe that when it comes to conflict between science and other modes of discovery - common sense, naïve perception, religion, philosophy - it is never our scientific theories that are in the end wrong. ${ }^{1}$ I wish to show here that physicalism simply fails to entail these strong claims either about the imperialistic reach of physics or that in cases of conflict, that physics may never be corrected; it is a more moderate position than may appear from rough formulations.

\section{Fundamentality}

What is physicalism? A typical formulation is:

Physicalism: the view that the world is the way physics says it is That is to say, it is within physics and physics alone that one can find a true account of reality. But what does this entail? If physics doesn't ever mention spaghetti, does this mean the physicalist must deny its existence? Or what about the more interesting cases of phenomena that appear unaddressed by physics: free will, intentionality, consciousness, God? The answer is that no, physicalists do not typically deny the existence of spaghetti, nor free will, nor intentionality, nor consciousness (e.g. Dennett 1991, Jackson 1998, Montero 1999, Kim 2005); although God is a separate matter as I will explain shortly.

\footnotetext{
${ }^{1}$ This is strictly speaking weaker than a claim of outright infallibility that may be read into Haack's interpretation of scientism above, but this is what I take her to be suggesting. It is not that our scientific theories cannot be wrong. Of course they can. Science evolves and theories change. Rather, the idea is that in cases of conflict between a scientific theory and the result of some other method of inquiry, it is always that other method, not the scientific theory, that must be corrected or reinterpreted.
} 
And this is so even despite the fact that mainstream physics discusses none of these phenomena. Some physicalists, Alex Rosenberg $(2012,2016)$ is a good example, adopt a strong scientistic attitude, and accordingly reject what is not mentioned by physics. But here these physicalists go beyond what is required by physicalism.

The reason why physicalism per se does not entail eliminativism about those entities or phenomena not mentioned by physics is made transparent by noting that more carefully formulated, physicalism is not a position merely about what exists, but rather about how the world is fundamentally:

Physicalism: the view that the world is fundamentally the way physics says it is And of course one may accept this claim, accept that physics does not mention spaghetti, and nonetheless accept its delicious existence. The consequence will simply be that spaghetti does not exist fundamentally. The same applies for free will, intentionality, and consciousness. According to the physicalist, these are not fundamental phenomena. And so their existence is compatible with physicalism given this more accurate formulation. The case of God must be treated differently for the simple reason that theists typically endorse not merely the claim that God exists, but that God is a fundamental being. And so, given that physics does not mention the existence of God, at least this typical kind of theism will be in tension with physicalism. ${ }^{2}$

All of this raises the question of what it means to say that something is fundamental. What is the difference after all between existing and fundamentally

\footnotetext{
${ }^{2}$ How might one argue that God exists as a nonfundamental being, so that theism is not in tension with physicalism? One might claim that God is simply the totality of the cosmos as described by physics, or more contentiously, that God is a fictional character, one whose being is constituted by other nonfundamental physical objects like religious texts and people's beliefs (see e.g. Schaffer 2009).
} 
existing? This is a vexed topic for philosophers, but there are a couple of ways to understand it that have been developed in metaphysics.

On one way of thinking about fundamentality, our fundamental theories provide a catalog of the entities in terms of which all others are built or made up. ${ }^{3}$ The nonfundamental entities are those that are built up out of the fundamental entities. The character of this building relation will vary depending on the types of entities one finds in the fundamental domain and the types of entities one wants to see as constituted out of them. ${ }^{4}$ It could be that the fundamental physical entities are the parts out of which everything else is built up mereologically (Oppenheim and Putnam 1958) or that the fundamental physical entities realize the nonfundamental in being the things that play the causal roles constitutive of being strands of spaghetti or cells or organisms (Putnam 1975, Melnyk 2003). Many argue that physical entities should be viewed as constituting a supervenience basis for all other facts so that once all of the facts about the arrangement of physical objects and features are fixed, the existence of everything else follows necessarily (Lewis 1983, Jackson 1998, Stoljar 2015). There is a contentious debate among physicalists about whether mere supervenience of all facts on the physical facts is sufficient for physicalism. Some insist that unless we can find some entities in the physical domain to identify with our target phenomenon, physicalists should deny their existence (Polger 2004, Kim 2008, Ney 2008), even if the relevant supervenience relations obtain. But the point remains, many physicalists are happy to accept the existence of entities not explicitly mentioned by physics as long as they may be viewed as built out of, realized by, identified with, or supervenient upon physical entities.

\footnotetext{
${ }^{3}$ See the various formulations in Melnyk (2008).

${ }^{4}$ See Bennett (2011) for a survey of the various kinds of building relations.
} 
There is another way of understanding the physicalist's claim that the world is fundamentally the way physics says it is. The difference here is subtle, but it is worth mentioning as this latter interpretation of fundamentality has become influential in recent years. Start by thinking of the fundamental not as a collection of objects, but rather as a collection of facts or theories. The fundamental domain then will be something like a comprehensive theory of the way the universe is so that all facts ought to have a complete explanation or grounding in these facts the theory describes. The explanation of nonfundamental facts in terms of the fundamental theory may be complicated and indirect, but if there are to be any nonfundamental facts, they must have an ultimate explanation in terms of this theory. This is a perspective (really a class of perspectives) on fundamentality developed by Gideon Rosen (2010), Ted Sider (2011), and Kit Fine (2012). It is a useful alternative way to think about fundamentality because sometimes when we are trying to see the connections between physics and our pre- or non-scientific beliefs, we are not interested so much in accommodating the existence of a particular entity or class of entities in a physicalist ontology, but rather trying to see how a certain set of facts may obtain given what we know physics says.

To give an example, no physical theory mentions anything about morality, what would be ethical or unethical to do in a certain situation, how to be a good person and flourish in the world. And yet one might reasonably think there are moral facts, such as that the arbitrary killing of innocents is wrong. Since the physicalist believes the world is fundamentally the way physics says it is, if there are to be such moral facts according to the physicalist, there must be some way of understanding how these facts may possess an ultimate explanation in physical terms. The explanation of how morality fits into a 
fundamentally physical world will likely be complicated and need to proceed in stages. A physicalist might, for example, explain the moral facts in terms of facts about human desires and plans or suffering, then explain these psychological facts in turn using facts about certain neurobiological processes, and then finally provide a physical explanation of these. The mark of success for such an explanation is, after all is said, that there be no leftover questions remaining about whether if our physical theory is true, the arbitrary killing of innocents is wrong. We can see in this example how the second understanding of what it means for physics to be fundamental is more appropriate than the first. What we are looking for when we attempt to accommodate morality in a physical world isn't a way of seeing some distinctively moral entities as built up out of physical entities, but instead a way of finding explanations for moral facts in the terms of physical theory.

Properly understood, we may now see that physicalists are not forced to be skeptics about spaghetti or morality or in general what is not mentioned in our physical theories. So long as these phenomena may be seen as constituted out of or explained by the more fundamental physical theory, they may be accepted, even embraced by the physicalist, even if they are never mentioned by physics. ${ }^{5}$ Establishing this suffices to show that physicalists need not think that the sciences or physical science should be expanded to cover more or all domains. For the physicalist is committed only to physics's successful description of the fundamental. ${ }^{6}$ Other sciences, ordinary perception,

\footnotetext{
${ }^{5}$ See also Poland (1994) who emphasizes that the physicalist is only committed to physics's providing "realization, determination, and explanation of all that there is in nature" (p. 298).

${ }^{6}$ She need not deny the obvious fact that physics in fact covers more than the fundamental. There are of course solid state physicists, astrophysicists, etc. whose job is at least partially to study nonfundamental physical phenomena. But the physicalist's central position only concerns physics's ability to discover the fundamental.
} 
introspection, philosophy, the examination of literature and art, and perhaps even common sense all may provide legitimate (even essential) means of discovering various realms of nonfundamental facts. The task of connecting the nonfundamental to the fundamental through constitutive or grounding explanations falls some of the time to the physicist (for example in quantum mechanical explanations of atomic and molecular states and chemical reactions or electrochemical explanations of biological processes). But just as often such inter-level explanations fall to scientists in other disciplines or even philosophers (as in the sort of explanations of morality mentioned earlier). And so to know all of the facts, one must move beyond physics. Physics doesn't have the resources to discover everything or all of the facts (only those that are fundamental).

Still, there might be a concern that there are limits to what these other methods of inquiry might show us. Sure, the physicalist might allow that we may make legitimate discoveries using naïve perception or common sense, discover the existence of genuine entities. But there is still a concern that for these methods to allow us to state facts or discover more of what there is, there remains a constraint, namely that these discoveries and postulates be compatible with and explainable in terms of what is provided by our physical theories, and thus that physics is the final arbiter of what is true and real. Is this not still scientism?

\section{Hempel's Dilemma}

The key will be to recognize that the way physicalism regulates one's beliefs about what sorts of things fundamentally exist, what is real and true, is dynamic and evolving. Physics and more broadly the physical sciences change and so the physicalist's view of 
the fundamental (if she is informed) will change as well. From what we have just noted, it is clear that even if the physicalist were committed to everything's possessing an explanation in terms of one static physical theory, this would still not be scientism in the sense that that position was characterized in the opening pages of this essay, namely as the view that science should expand to cover more or perhaps all domains of inquiry, since there may be better means of grasping the nonfundamental. ${ }^{7}$ But we just saw there is a worry that because according to the interpretation of physicalism we have been considering, all nonscientific facts must be explainable by physical theories, all entities discovered by nonscientific means must be constituted out of physical entities, that where this is not so, the physicalist must deem the putative nonfundamental facts non-facts; the entities discovered by nonphysical means non-entities. And so for the physicalist, it looks as if the successes of nonscientific or nonfundamentally scientific methods of inquiry are contingent on whether they may be fit into the picture of the world we recover from physics. If a nonscientific or nonfundamentally scientific claim is one for which it is difficult to see how it could be fit into the picture of the world we get from physics, then the physicalist must reject it. And then it looks as if physicalists are committed to what I above referred to as a corollary of the scientistic position, that in cases of conflict between science and other modes of inquiry, it is never the scientific theory that must be revised. The physicalist doesn't avoid scientism after all.

We will see why the physicalist is not committed to what I am calling this corollary of physicalism by way of considering a puzzle the physicalist faces, a puzzle that arises out of the dynamic and changing character of physics and physical theories. It

${ }^{7}$ For defense of this as a reasonable characterization of scientism, see Peels (2016). 
is by recognizing and addressing this puzzle that we may better understand why the physicalist is not committed to rejecting verdicts of other methods of inquiry even when they appear difficult or even impossible to reconcile with physical theory. So let us put scientism to one side momentarily and see the issue.

Following the interpretation of the previous section, physicalists believe that the world is fundamentally the way physics says it is. But what are we talking about when we say the world is fundamentally the way physics say it is? The most obvious thing this might mean is that the world is fundamentally the way our best current physical theories say it is. This would then suggest that physicalism is the claim (depending on how we understand fundamentality talk) that everything there is is built out of the entities mentioned by our current physical theories, or that every fact has an explanation that bottoms out in the claims of our current physical theories. But if this is what physicalism comes to, then physicalism is straightforwardly false. For as successful as physics has been, the end is not yet in sight. Physics includes claims that will most definitely be corrected by future theories, and there remain many phenomena within its own domain that physics does not yet have the resources to explain. To emphasize how far we are from having in our hands such a true and complete physical theory, consider how many results taken for granted by our best confirmed and most resilient theories, such as the Standard Model of particle physics, are continually being revised by experiment. For example, until the late 1990s and the Nobel prize winning work of Kajita and McDonald, it was assumed that the Standard Model was correct in its claim that neutrinos lack mass. Experimental work now continues trying to give us a more accurate picture of the nature of these particles, including a precise value for their mass. Or, for a case in which we 
know there is even more we have to learn, consider the discoveries of dark matter and dark energy. These strange new phenomena are estimated to make up $27 \%$ and $68 \%$ of our universe respectively and we have nearly no idea what they are. Even when it comes to what we do seem to know, what we've learned about matter from the extremely successful quantum field theories making up the Standard Model and about space-time from general relativity, these too reveal the limitations of current physics. For these two pillars of fundamental physics have yet to be reconciled into a single consistent theory. Doing so, it is widely recognized, is a far from trivial task and will require significant revolutions in physics.

So we have good reason to believe that the world isn't, as a matter of fact, fundamentally the way current physics says it is. However maybe this isn't the only possible way to interpret the 'physics' in physicalism. Maybe instead of understanding physicalism as the view that the world is fundamentally the way current physics says it is, we should take it as the view that the world is fundamentally the way the future, true, final, completed physical theory says it is. This interpretative strategy relieves physicalism of the problem of being false and so has been embraced by many philosophers (Lewis 1983, Loewer 2001, Dowell 2006). However, as many others have noted, there are problems with this construal of physicalism as well. I'll discuss three.

First, many view physicalism as committing its adherents to at least some substantive ontological claims about the nature of our world. Physicalists believe in fermions and bosons, electromagnetic fields, quantum entanglement, gravitation, and curved space-time. But since no one now knows what future physics will look like, no one knows whether any of these things will be preserved by the time (if there is a time) in 
which physics is completed. Physics could continue for millennia and just as the things physics postulates today look very different from what was postulated a millennium ago, we can't be sure what future physical theories will contain. And so if physicalism is supposed to be the view that the world is the way this future, completed, true, but unknown theory says it is, then we don't really know what physicalists are committed to (Hempel 1980).

A second concern some have raised (Montero 1999, Chomsky 2003) is that understanding physicalism as the view that the world is fundamentally the way the future, completed physical theory says it is threatens to make the view trivial. This is because one might think that for physics to be completed, it will have to expand to have the resources to explain all of the phenomena that exist in our world. Physics differs from other scientific theories like biology, psychology, and economics precisely in having within its purview the fundamental structure of the universe and all objects in it, not a subset of those objects. Physics doesn't just study living systems or thinking systems or financial systems. It studies all systems. But if this is so, then it is a trivial matter that the world is the way that a completed physical theory says it is, since that by definition would be a complete theory with the resources to explain everything.

One illustration of how this way of understanding physicalism threatens to trivialize the position concerns the case of phenomenal consciousness. Most of those who reject physicalism today, e.g. dualists (Nagel (1974), Chalmers (1996)), do so because they think that physics is in principle incapable of capturing the existence of phenomenal consciousness, that our experiences have certain qualities constituting the way they look, feel, taste, and so on. The thought is that no amount of information about the distribution 
of matter or charges or gravitation will be able to explain the way pains feel or strawberries taste. But suppose the dualist is right. Then for physics to be completed, for it to have an account encompassing everything, it can't rest at giving a complete account of the distribution of matter and charges and the like. It must also add descriptions of all of the various kinds of conscious experiences one might have. So suppose at some time in the future, to have a complete description of everything, physics expands and supplements its theories with the postulation of additional phenomenal features: tastes, smells, bodily sensations, and so on. This would be a scenario in which the world was fundamentally the way the true final completed physics says it is. But intuitively it would be a situation in which physicalism turned out to be false - the central debate between physicalists and dualists after all turns on this very issue, whether we need to postulate qualitative features of experience as additional, fundamental features of the world. And so it seems that we cannot understand physicalism as the view that the world is the way the completed future physics says it is. This would be to make physicalism trivial, consistent with the existence of just about anything.

So our first two problems are that the understanding of physicalism as the view that the world is the way a final, completed physics says it is makes the view contentless (unable to say anything positive about what the world contains) and trivial. Finally, the third problem with this formulation of physicalism concerns an assumption that this way of seeing physicalism commits the physicalist to, an assumption that is contentious and should really be orthogonal to the issue of whether physicalism is correct. This is the assumption that there at some point will be a final, completed physical theory. To see why it is contentious whether there will ever be such a theory, consider the many 
obstacles standing in the way: computational limitations, bounds on human ingenuity, restrictions in financial or other resources, the possibility of apocalyptic scenarios like catastrophic climate change, and so on. But whether a completed physical theory is ever actually achieved is not relevant to the question of physicalism as it matters to many of us today. Here we may take the opportunity to say a bit about what it is exactly that the physicalist is interested in when adopting this position so we can see why it does not require the existence of a final, completed theory.

There are three main components to physicalism or what it is to be a physicalist. The first is that by adopting physicalism, one makes some substantive positive claims about what the world is like. The physicalist is one who takes the lessons of physics seriously, so (as mentioned already) she believes in what physics has shown us to exist so far: electrons and electromagnetic fields, curved spacetime, quantum entanglement, superconductivity, and on and on. Someone who believed in nothing but spaghetti or rocks or the power of love would not be a physicalist. ${ }^{8}$ Second, being a physicalist also involves having some negative commitments at a given time regarding what the scientific community has good reason to believe is incompatible with or not capable of explanation by current physical theory. So a physicalist, qua physicalist, will reject the existence of things like entelechies, Cartesian souls, irreducible vital or mental forces, and so on. Third, so long as physics has not yet reached completion, physicalists have the expectation that (near) future physical theories will continue to improve in their ability to

\footnotetext{
${ }^{8}$ How exactly to understand the positive commitments of the physicalist will depend on how the physicalist addresses the issue of scientific realism. A physicalist may be an object-oriented scientific realist, a structural realist (one who commits only to the structure of physical theories), or even a constructive empiricist (being committed only to the empirically accessible consequences of our physical theories).
} 
accurately describe our world and provide the basis for explanations of the nonfundamental.

These central components of the physicalist's position together distinguish her from the idealist or dualist. But none commits her to the view that at some point in the future, physics will be completed, that it will ever have an account of everything. The physicalist, knowing that physics is not now finished and has a lot left to explain, will believe that future physical theories will improve on current ones. She may also be committed to the fact that physics, rather than other theories, is in the best position going forward to eventually reach a complete theory. But this is not the same as saying it will reach this complete theory. Agnosticism on the issue of a final, completed physics does not undermine physicalism and the positive and negative attitudes just described. And so the position should not be defined as one that can only be correct if there is such a thing as the final, completed physical theory.

So we have seen two alternatives for how to interpret physicalism: one that interprets it as the claim that the world is fundamentally the way current physics says it is and the other that has it as the claim that the world is fundamentally the way some future, completed physics says it is. The first interpretation makes physicalism false; the second makes it unsubstantive, trivial, and potentially meaningless (if there is never any completed physics). So both options are problematic. This problem for interpreting physicalism has come to be known as Hempel's Dilemma, after Carl Hempel who perhaps first noted this difficulty in defining physicalism (Hempel 1980). Note (as Hempel himself did) it will not help to define physicalism instead in terms of some 
future, moderately improved theory striking a middle position between the two horns of the dilemma, for example, in the way David Lewis did:

[Physicalism] is the thesis that physics - something not too different from presentday physics, though presumably somewhat improved - is a comprehensive theory of the world, complete as well as correct. (Lewis 1983)

For even though this will do better at making the content of physicalism clear to us and we can be sure there will still be slightly better physical theories in the future, and it isn't trivial that such a theory will be correct, we have only slightly less reason to say that this theory will be false. As has already been noted, as of right now, we have good reason to think any near descendent of current physics will be missing out on a lot and need to be replaced with a more accurate and more complete theory. To get close to completion, physics will have to undergo substantial revolutions.

Some look at this problem for defining physicalism and conclude that it is impossible to make sense of the position and so it is hopeless and we should all set physicalism aside (Crane and Mellor 1990, Stoljar 2010). However, as I have argued elsewhere (Ney 2008), there is a solution to this problem and that is to reject the assumption that physicalism is a descriptive proposition or claim that the world is the way this or that physical theory says it is. Instead, following Bas van Fraassen (2002), it is best to conceive of physicalism as a complex psychological attitude. And so it is a position in a broader sense, a stance one takes towards the world. The complex attitude involved in being a physicalist primarily involves the three components mentioned above: the two positive and the other negative. One is a physicalist insofar as one has the disposition to form ontological and more broadly metaphysical commitments to the kinds 
of things and propositions our best, orthodox, current physical theories describe and one does not form commitment to those things we have good reason to believe is incompatible with or cannot be explained by current or future physical theories. Physicalism is also constituted by the expectation (so long as physics has not reached completion) that future physical theories will continue to improve in their ability to describe the world as it is. A reasonable physicalist will also recognize, as she should be informed about current physics, although this is not an essential part of the position, that physics does not have anything close to the final theory. ${ }^{9}$ Note that physicalism is not partly constituted by the belief that the world is the way current physics says it is. This is something any reasonable physicalist should reject. The physicalist, qua physicalist, will have beliefs that the phenomena described by our (best, orthodox) current physical theories exist. She will believe in the existence of electrons, electromagnetic fields, curved space-time, and so on, and not believe in irreducible qualia or entelechies. (Note these specific beliefs are not required by physicalism per se. Rather one who holds the physicalist attitude will be disposed to believe in whatever she believes current physics says exist.) But this is strictly speaking different from believing that the world is simply the way this theory says it is.

Some object to this understanding of physicalism, which ties the physicalist's metaphysical commitments to current physics, that it does not improve sufficiently on the first interpretation of physicalism we discussed. Adopting the physicalist attitude I describe still commits the physicalist to what are probably lots of false beliefs since we

\footnotetext{
${ }^{9}$ In the future, as physics develops and hopefully gets closer to completion, the physicalist will believe that physics is closer to having the complete theory.
} 
know physics will have to be revised significantly on its way to completion. And so physicalism, even if it is an attitude, can seem to amount to a bad attitude.

This is an interesting feature of the position, but I do not think it makes the interpretation of physicalism wrong. Rather, what bringing out this objection shows is that the physicalist is one who, to a certain extent, sticks her neck out in the sense that she adopts commitments to lots of things some of which she acknowledges might turn out not to be real. The situation of the physicalist is similar to one facing the familiar paradox of the preface. ${ }^{10}$ The physicalist has excellent reason for each of her beliefs: in the existence of electrons, in quantum entanglement, in curved space-time, and so on. But she also has excellent reason to believe at least some of these beliefs are false. She doesn't know which ones since there are always very many opposing views about the correct way to extend current physics. Now one might think that given the fact that she has good reason to believe physics will undergo substantial revolution that all of these beliefs are false. But this probably isn't so. For typically after theory change, it isn't that all earlier postulates of a theory are rejected. Of course some postulates are rejected (as most believe was the case with Cartesian souls, phlogiston, and the ether), but what often happens is that what was thought to be some kind of fundamental phenomenon is revealed to be explainable in terms of something more fundamental underlying it and so the commitments are thereby preserved. So the physicalist, precisely because each of her

\footnotetext{
${ }^{10}$ The preface paradox (Makinson 1965) is that facing the writer of the work of nonfiction who after carefully researching all of the very many claims made in her book recognizes that given human fallibility, it is likely she made at least one mistake somewhere. So to be honest, she acknowledges this fact in her book's preface. In this (common) situation, the author has excellent reason for making each claim in the main text of the book. But she also has excellent reason to believe at least one of these claims is false. Thus the paradox.
} 
commitments has been so well justified, has good reason to believe many of her individual commitments won't be shown to be false. There will likely be some future theory to explain most of them. And so she can still be confident in each of her commitments and the picture they provide of fundamental reality.

\section{Physicalism and Scientism}

We can now bring the discussion back to the question of scientism. The way things were left at the end of Section 2, we saw that the physicalist has no problem allowing that there are many facts that are not at all mentioned by physics and so may be discovered by other scientific as well as by nonscientific methods of inquiry. Indeed she might believe other methods are best placed to discover nonfundamental truths. This is unquestioningly accepted by the physicalist since her claim is not that the only facts there are are those described by physics, but instead that physics provides a fundamental set of claims that can provide explanatory grounds for all others. There was still a concern however that this limited the role of other domains since for the physicalist, other disciplines or methods look to still be ultimately required to agree with what is established by physics, since to be legitimate, their discoveries must all have an explanation in terms of physics. Moreover, if there is ever a conflict between physics and the results of another method of inquiry, the physicalist must always side with the verdict of physics. And this looks still rather scientistic.

If physicalism is simply the thesis that the world is fundamentally the way current or a final, completed physics says it is, then this, I think, is the conclusion we are left with. Physicalism is committed to a form of scientism, at least by commitment to what I 
earlier called a corollary of scientism. Other disciplines can make discoveries, but then to be legitimized, these must be explained by our best current or final physical theories. And so if there is a conflict between some verdict of another means of inquiry and physics, then it is the former that must be tossed out. But as I have just argued, this is not the correct way to understand physicalism. Physicalism isn't the proposition that the world is the way some specific physical theory says it is. Instead it's an attitude that involves believing in the kinds of things that current physics says there is and not believing in what one believes is incompatible with or cannot be explained in terms of current physics, with the expectation that future physical theories will be able to explain more. But this leaves a lot of room open for what we might learn about from other disciplines. The physicalist indeed may have a four-fold classification of putative entities and facts:

1. What is described by current physics

2. What possesses an explanation in terms of current physics or may be seen as constituted by the entities of current physics

3. What it is reasonable to believe will never have an explanation in terms of current or near future physics or ultimately be seen as constituted by the entities of current or near future physics

4. What it is not reasonable to believe cannot ultimately be explainable in terms of, or seen as constituted out of entities of current or near future physics The last three categories correspond to the results of nonscientific or nonfundamental scientific methods. We have already discussed those falling under the second category and how belief in them is compatible with physicalism. But we may now see that the physicalist attitude is also compatible with belief in facts or entities in the fourth 
category. Nothing in the physicalist attitude commits the physicalist to rejecting what falls in this category. She must only have the expectation (and as we saw, this is one component of the physicalist attitude), that those facts that now lack explanations in terms of current physics may be explained in the future by the resources of current or near future physics, and that do not presently have an account of their constitution out of the entities of current physics, may be reasonably seen in the future as constituted out of the entities of current or near future physics.

To see this more concretely, consider again the case of phenomenal consciousness. Most philosophers believe that there are such things as phenomenal features of experiences, qualia. We have very good reason to think that pains hurt (they feel a certain way), that there is something it is like to taste a strawberry ${ }^{11}$, and so on. This is so even though at this stage, physical science has not progressed to the point of providing an explanation of how these phenomenal features arise from physical matter. Some have argued that there is good reason to think that qualia are irreducible in a strong sense, that they could never be explained in terms of a physical science nor do they supervene on physical phenomena (Nagel 1974, Chalmers 1996). If the physicalist accepts these arguments and their conclusion that qualia are indeed irreducible, then the physicalist may reject their existence. This would be to view them as falling under the third category above - what is irreducible can never be explained physically. However another option is to think that qualia may be unexplained but at the same time physical, and that a future more complete understanding of physical theory will allow for their

11 Perhaps this is different for different people. 
understanding. This is a way of viewing them as falling under the fourth category above. This is to reject only the current reducibility of phenomenal features not their existence.

With respect to phenomena that we have good (perhaps nonscientific) reason to believe exist but do not yet have a physical explanation, so long as there is no compelling reason to think their existence cannot be explained by current or near future physics, the physicalist may believe in them or remain neutral. The physicalist need not think that everything there is has an explanation in terms of her current physical theory for the simple reason that physicalism does not commit her to saying that science is complete.

Moreover, it is not incompatible with physicalism that what we learn using nonscientific methods (like introspection or naïve perception or even common sense) can motivate changes to or reinterpretations of current physical theories. For example, one of the main philosophical challenges for quantum mechanics is what is known as the measurement problem. This is the problem that the laws of the theory entail that systems may evolve into states in which it is indeterminate what features they have, where they are located or how fast they are moving. Erwin Schrödinger famously used this consequence of quantum mechanics to show that given a simple experimental setup, the theory would predict that a cat could be put into a state in which it was indeterminate whether it was alive or dead. We don't ever observe states like this. Instead what we find upon measurement is that physical systems are always in determinate states of position or momentum, whether they are living or dead. This is the measurement problem: how to reconcile (i) the fact that quantum theories permit systems to evolve into states that are 
indeterminate with (ii) what we learn from naïve perception ${ }^{12}$, even common sense. ${ }^{13}$ It is possible to take a strong scientistic approach to this problem, arguing that scientific theories cannot reasonably be challenged this way. One may dismiss the problem as merely philosophical and not something scientists need concern themselves with. Another response to the problem, which strikes me as similarly scientistic ${ }^{14}$ is to embrace the consequences of quantum mechanics and argue that they don't actually conflict with our experience. If our scientific theory says that systems must evolve into states that are indeterminate, then despite appearances, this must be so. This is a strategy that was proposed by the physicist Hugh Everett in the 1950s; it is now referred to as the many worlds theory. The core idea is to argue that when a quantum system is in a (pure) state that is indeterminate between $\mathrm{A}$ and $\mathrm{B},{ }^{15}$ this means there is a system that is genuinely in both state $\mathrm{A}$ and state $\mathrm{B}$. To reconcile this with the fact that a human observer will always see only one state A or B in a given instance, Everett suggested that just as both states are present, so two observers are present. So there are never indeterminate experiences. One observer will always see A and the other will see B (Everett 1957). The result is a theory very much in tension with common sense and background beliefs about how many objects and observers may exist in any given location. However, if one wants to maintain the original scientific theory, sticking to it even in the face of challenges from perception and common sense, then Everett provides a way to do this.

${ }^{12}$ By 'naïve perception,' I simply mean to refer to the ordinary use of perceptual (visual, auditory, etc.) faculties, rather than the more sophisticated perceptual techniques used in scientific research.

${ }^{13}$ A now classic introduction to this problem may be found in Albert (1992).

${ }^{14}$ Though more reasonable since rather than ignoring perceptual facts, it tries to reconcile them with the scientific theory.

${ }^{15}$ By saying 'pure state,' I mean to indicate that the indeterminacy is not due to our ignorance of the full details of the situation, but rather is a feature of the system itself. 
On the other hand, one might argue it is reasonable to pursue a less scientistic approach, that naïve perception and common sense do give us reason to revise quantum mechanics to avoid these puzzling consequences. Although no such revision to quantum mechanics is widely accepted, many have been proposed. ${ }^{16}$ What I wish to point out here is that recognizing the flaws in quantum mechanics, that there is a measurement problem, is not at all in tension with the physicalist attitude. Not knowing which part of quantum mechanics exactly will have to be revised in order to solve the measurement problem, the physicalist will adopt the ontological commitments entailed by current formulations, while expecting that future formulations will do better at reconciling the theory with perception and common sense.

To conclude this section, we may consider more generally what happens in a situation in which physical science and the results of other methods of inquiry appear to conflict and compare how this looks from the perspectives of physicalism and scientism. Those with a scientistic attitude face a choice about what to do with the recalcitrant information. The choice is between eliminativism and compatibilism. Scientism forces one to reject the claim that is in tension with scientific theory or find a way to reinterpret what seems to conflict with the scientific theory so that it no longer conflicts. In some cases, we have seen, this will lead to a tension with common sense. However, the physicalist will recognize that current physics is incomplete, and that in order to improve on current formulations, the scientist may need to acquire information using other nonscientific or nonfundamentally scientific methods. Though the physicalist will as part of her commitment have an expectation that future theories will be better at explaining

${ }^{16}$ See Albert (1992) again for a useful overview. 
recalcitrant phenomena, she need not believe there will ever be such a theory. It may in the end be impossible to provide explanations of these phenomena in terms of physical theory. ${ }^{17}$ And so physicalism permits a third way (neither eliminativist nor compatibilist), of tolerating the tension, in contrast to the imperialism of the scientistic attitude.

\section{The Domain of Physicalism}

So far, in discussing the places where physics may seem to come into conflict with the results of other methods of inquiry, I have assumed the recalcitrant information involves a particular subject matter. All of the examples I have used concern factual information about actual and contingently existing objects known about through a posteriori means. However, when we think about all of the means by which we may acquire information and all of the facts we might learn by scientific or nonscientific means, some concern not how things actually are, but what is possible. Some concern not what may contingently exist, but rather what is necessary. Some concern the nature of things, basic matters of metaphysics. Some concern mathematical truth. Some concern not objective factual information at all, but rather information that is subjective in some respect, such as that concerning matters of taste, or normativity, concerning what one ought to do or believe.

The key difference between these topics and the examples that were discussed above is that in each case there is reason to think that these facts cannot even in principle find explanations in terms of current or even any future physics. And this is because there may be reason to think that in each case the subject matter is not about how our world is

17 A predecessor here is McGinn (1989). 
as a matter of fact. This is why these facts cannot be derived from facts about how physically our world is.

What to say about each of these cases is an issue on which physicalists will differ, but many recognize that although physics aims at comprehensiveness, it is not a comprehensiveness on all matters. For example, Jeffrey Poland claims that:

We should understand that [physicalist] theses are concerned only with the natural order, with the universe in which we live and interact. Physicalism applies to all claims that are objectively true or false in nature. This means that the theses do not apply to abstract realms, if there are any: mathematical structures, universals, propositions, and the like. (1994, p. 227)

Interestingly, Poland does believe that the aesthetic and the moral lie in the domain of physicalism, since he claims, these do concern the natural order. Andrew Melnyk restricts his physicalism to concern only those things that exist contingently or play some sort of role in the causal order $\left(2003\right.$, p.10). ${ }^{18}$ So, if mathematical entities or universals are necessary existents and don't causally interact with anything, then their existence would also fall outside of the realm of concern for a physicalist of Poland or Melnyk's stripe. A physicalism restricted in this way would thus open the door for legitimate nonscientific or nonphysical methods of investigation into some topics lying in the third category above.

What about those domains just mentioned for which it is more plausible that the relevant topics do concern the natural order, what there is in our world and how it must

\footnotetext{
${ }^{18}$ Frank Jackson stays neutral on this issue stating physicalism "claims that a complete account of what our world is like, its nature (or, on some versions, a complete account of everything contingent about our world), can in principle be told in terms of a relatively small set of favoured particulars, properties, and relations, the "physical' ones" (1998, p. $6)$.
} 
be? Here, we must distinguish different cases. Although modal facts about what is necessary and possible may seem not to depend on the results of physics, some argue that there is nothing beyond the kind of necessity and possibility we find in the laws of physics (e.g. Shoemaker 1998). Objective normative, e.g. moral, aesthetic, and epistemic facts may also perhaps find an explanatory basis in physics. Providing such bases has been a long and difficult research program involving many philosophers. ${ }^{19}$ If such projects are successful, then normative facts may again fall under the fourth category of facts and entities described in Section 4: facts that we discover using nonscientific or nonfundamentally scientific methods, and those it is consistent for one with the physicalist attitude to endorse since there is no reason for her to believe they will not be explained using the resources of current or near future physics.

So, there may be reason to hope that even if the realms of modal and normative facts may be within the purview of physicalism, commitment to them may be compatible with physicalism even if these facts do not yet possess physical explanations. However, one might think there are a further class of facts that are about how our world actually is and yet these are not even in principle capable of physical explanation. In particular, some have argued that the questions of metaphysics concern the nature of our world as it actually is and yet are not explainable in terms of physics because they are more fundamental than the physical facts (Paul 2012) or they are much broader and abstract (Sider 2008). For example, metaphysicians may discuss deep questions about physical objects (whether they are mere bundles of properties or properties inhering in substrata,

${ }^{19}$ For approaches to explaining epistemic normativity, see Hazlett (2013). For one among very many approaches to explaining morality, see Jackson (1998). 
how or even if they may persist through change over time, whether time is in fact real, and what essential features if any objects possess).

Physicalism is compatible with a range of views about the status of metaphysical questions. One may reject them wholesale. One may argue that there is no sharp way to make the distinction between questions of physics and questions of metaphysics. One may view metaphysics and its methods as distinct from those of physics, but view it as a way of getting a deeper understanding of the same facts that physics investigates.

Physics, for example, may claim that there are fermions and bosons, where metaphysics may fill in what we are talking about when we talk about fermions and bosons. In this way, metaphysics may be viewed as a way of interpreting the claims of physics. Alternatively, a physicalist might regard metaphysics as an enterprise that is not trying so much to state facts about the nature of the world, but rather to offer alternative pictures to supplement the physical story and try to get a better imaginative grasp on the theories physics provides (Ney 2012). Holding the physicalist attitude certainly puts constraints on what one may reasonably believe one can learn from metaphysics: for example, it rules out a view according to which metaphysics provides access to a realm of fundamental truths altogether distinct from the truths of current physics. But as we have just seen, we can see that physicalism is compatible with a range of ways of accommodating a fertile discipline of metaphysics.

\section{Conclusion}

So we have seen that although superficially, physicalism may seem to amount to something like a reductionistic version of scientism, by paying attention to more subtle 
and careful formulations of the position, we can see that the physicalist need not be scientistic. Indeed, when the physicalist properly acknowledges the limitations of current physical theory, she can acknowledge with modesty the possibility of gaining valuable information from other domains of inquiry, not just for matters not discussed by physics but to help guide physics in the agenda it sets for itself as well.

\section{Work Cited}

Albert, David Z. 1992. Quantum Mechanics and Experience. Cambridge: Harvard University Press.

Bennett, Karen. 2011. Construction Area (No Hard Hat Required). Philosophical Studies. 154(1): 79-104.

Chalmers, David. 1996. The Conscious Mind. Oxford: Oxford University Press.

Chomsky, Noam. 2003. Replies. Chomsky and His Critics. L. Antony and N. Hornstein, eds. Oxford: Blackwell.

Crane, Tim and D.H. Mellor. 1990. There is No Question of Physicalism. Mind. 99(394): 185-206.

Dennett, Daniel. 1991. Consciousness Explained. Boston: Little Brown.

Dowell, Janice. 2006. Physicalism: Empirical, Not Metaphysical. Philosophical Studies. 131(1): $25-60$.

Everett, Hugh. 1957. Relative State Formulation of Quantum Mechanics. Review of Modern Physics. 29: 454-462. 
Fine, Kit. 2012. Guide to Ground. Metaphysical Grounding. F. Correia and B. Schnieder, eds. Cambridge: Cambridge University Press.

Haack, Susan. 2012. Six Signs of Scientism. Logos and Episteme. 3(1): 75-95.

Hazlett, Allan. 2013. A Luxury of the Understanding. Oxford: Oxford University Press.

Hempel, Carl. 1980. Comments on Goodman's Ways of Worldmaking. Synthese. 45(2): 193-199.

Jackson, Frank. 1998. From Metaphysics to Ethics. Oxford: Oxford University Press. Kim, 2005.

Kim, Jaegwon. 2008. Reduction and Reductive Explanation: Is One Possible Without the Other? Being Reduced: New Essays on Reduction, Explanation, and Causation. J. Hohwy and J. Kallestrup, eds. Oxford: Oxford University Press.

Lewis, David. 1983. New Work for a Theory of Universals. Australasian Journal of Philosophy. 61: 343-377.

Loewer, Barry. 2001. From Physics to Physicalism. Physicalism and its Discontents. C.

Gillett and B. Loewer, eds. Cambridge: Cambridge University Press.

Makinson, D.C. 1965. The Paradox of the Preface. Analysis. 25: 205-207.

McGinn, Colin. 1989. Can We Solve the Mind-Body Problem? Mind. 98: 349-366.

Melnyk, Andrew. 2003. A Physicalist Manifesto: Thoroughly Modern Materialism.

Cambridge: Cambridge University Press.

Melnyk, Andrew. 2008. Can Physicalism Be Non-Reductive? Philosophy Compass. 3(6): 1281-1296.

Montero, Barbara. 1999. The Body Problem. Nô̂s. 33(2): 183-200.

Nagel, Thomas. 1974. What is it Like to be a Bat? Philosophical Review. 83: 435-450. 
Ney, Alyssa. 2007. Can An Appeal to Constitution Solve the Exclusion Problem? Pacific Philosophical Quarterly. 88(4): 486-506.

Ney, Alyssa. 2008. Physicalism as an Attitude. Philosophical Studies. 138(1): 1-15.

Ney, Alyssa. 2013. Neo-Positivist Metaphysics. Philosophical Studies. 160(1): 53-78.

Ney, Alyssa. 2015. A Physicalist Critique of Russellian Monism. In Consciousness in the

Physical World. T. Alter and Y. Nagasawa, eds. Oxford: Oxford University Press.

Oppenheim, Paul and Hilary Putnam. 1958. The Unity of Science as a Working

Hypothesis. Minnesota Studies in Philosophy of Science. 2. Minneapolis: University of Minnesota Press.

Paul, L.A. 2012. Metaphysics as Modeling: The Handmaiden's Tale. Philosophical

Studies. 160: 1-29.

Peels, Rik. 2016. A Conceptual Map of Scientism. this volume.

Pereboom, Derk. 2011. Consciousness and the Prospects of Physicalism. Oxford: Oxford University Press.

Poland, Jeffrey. 1994 Physicalism: The Empirical Foundations. Oxford: Oxford University Press.

Polger, Thomas. 2004. Natural Minds. Cambridge: MIT Press.

Putnam, Hilary. 1975. Philosophy and Our Mental Life. Philosophical Papers. Volume 2. Cambridge: Cambridge University Press.

Rosen, Gideon. 2010. Metaphysical Dependence: Grounding and Reduction. Modality:

Metaphysics, Logic, and Epistemology. B. Hale and A. Hoffmann, eds. Oxford: Oxford University Press.

Rosenberg, Alex. 2012. The Atheist's Guide to Reality. New York: W.W. Norton. 
Rosenberg, Alex. 2016. Epistemological Challenges for Scientism (And How to Meet Them). this volume.

Schaffer, Jonathan. 2009. On What Grounds What. In Metametaphysics. D. Chalmers, D. Manley, and R. Wasserman, eds. Oxford: Oxford University Press.

Shoemaker, Sydney. 1998. Causal and Metaphysical Necessity. Pacific Philosophical Quarterly. 79: 59-77.

Sider, Theodore. 2008. Introduction. Contemporary Debates in Metaphysics. T. Sider, J. Hawthorne, and D. Zimmerman, eds. Oxford: Blackwell.

Sider, Theodore. 2011. Writing the Book of the World. Oxford: Oxford University Press. Stoljar, Daniel. 2015. Physicalism. The Stanford Encyclopedia of Philosophy.

Stoljar, Daniel. 2010. Physicalism. London: Routledge.

Van Fraassen, Bas. 2002. The Empirical Stance. New Haven: Yale University Press. 